\title{
Knowledge of Nigerian laboratory technologists and mortuary attendants on various methods of embalming techniques
}

\author{
Moyosore Salihu AJAO ${ }^{1 *}$, Ayokunle OLAWEPO ${ }^{1}$, Moses FALAIYE ${ }^{1}$, \\ Anthony Gbenga ADEFOLAJU ${ }^{1}$, Luqman Aribidesi OLAYAKI ${ }^{2}$, \\ Sikiru Adekunle $\mathrm{JIMOH}^{1}$ and Adesola Idowu ABIOYE ${ }^{1}$ \\ ${ }^{I}$ Department of Anatomy, Faculty of basic Medical Sciences, College of Health Sciences, University of Ilorin, \\ Ilorin, Nigeria. \\ ${ }^{2}$ Department of Physiology, Faculty of basic Medical Sciences, College of Health Sciences, University of \\ Ilorin, Ilorin, Nigeria. \\ *Corresponding author, E-mail: moyoajao@yahoo.com; Tel: +27724788234, +27781776441
}

\begin{abstract}
Embalmment is the method of preservation of bodies after death and in recent times, different methods have been developed in order to preserve the bodies more accurately and more perfectly. This study was designed to test the knowledge of Nigeria laboratory technologists and mortuary attendants on various methods of embalmment techniques. Semi structured questionnaire was administered to 72 randomly selected respondents comprising of laboratory and mortuary attendants $(94.4 \%$ males and 5.6\% females) from different Medical schools, teaching and general hospitals and funeral homes across the country. $41.7 \%$ of the respondents are laboratory technologists in anatomy departments, $48.6 \%$ are mortuary attendants and $7.9 \%$ are embalmers at funeral homes. All the respondents are very knowledgeable about the arterial embalmment while about $2.3 \%$ have some knowledge about plastination method of embalmment. We came to the conclusion that the respondents need to have training and re-training in various methods of modern embalmment techniques in order for them to cope with the day to day challenges required in embalmment services.
\end{abstract}

(C) 2010 International Formulae Group. All rights reserved.

Keywords: Preservation, Cadaver, Training, Medical schools, Anatomy, Plastination

\section{INTRODUCTION}

Preservation and presentation of cadavers dates back to the history of study of anatomy itself (Newell, 1995). Human cadavers remain the best way to provide 3dimensional pictures of anatomy to medical students, demonstrators, and other students of allied health sciences (Al-Zuhair et al., 1995). Dates as to the precise time of early embalming practices in Nigeria are difficult to gather because of the dating practices at that time, but in the global context, the history extend to hundreds of years earlier than previously thought (Koller et al., 1998). It has been practised in many communities and is one of the earliest surgical procedures undertaken by man (Ezugworie et al., 2009). The processes of embalming have changed over the years to what we know as modern day embalming (Fredrick and Strub, 1989; 
Mayor, 2000). Embalming is aimed at retarding desiccation and preventing fungal attacks on cadaveric tissue, owing to the tendency of biological tissues to decompose and putrefy with time. Many techniques for preservation of cadavers have evolved (Saeed et al., 2001). Today, teaching and studying of anatomical sciences are aided by the quality of embalming services (Barker and Silverton, 1998). Embalming services also help in medico-legal activities, provide financial justification and create an opportunity for loved ones to see the deceased before burial (Acherson, 1983).

The major constraint to embalmment was lack of religious support from early Christians, Muslims and Jewish customs who believed that burial should come immediately after death (Al-Bukhar, 1979; Jonathan, 1997). The earliest method of embalmment was mummification which started in Egypt (Armstrong, 1993), and advanced to the modern ones such as Petrification and Arterial (Lockhart, 1927; Spring et al., 1971; Ellis, 2001), cavitational embalmment (Von Hagens et al., 1987), and electrolytic coating and plastination (Von Hagens, 1979). American civil war and the need for preservation of body to permit burial without haste and prevention of infection eared the beginning of modern embalming techniques (Mayor, 2000). For many centuries, scientists have tried to evolve and create effective and health safe embalming techniques for conservation and long lasting preservation of corpses since most mummies and anatomical preparation in the past were besieged with many problems and thus stimulate challenges for continuous research (Sivrev et al., 2005). As a result of this progressive trend in which embalming techniques followed, this study was designed to assess the knowledge of Nigerian laboratory technologist and Mortuary attendants in various medical schools, teaching hospitals and funeral homes on modern methods and techniques on embalming.

\section{MATERIALS AND METHODS}

\section{Subjects and methods}

This was a descriptive cross-sectional study. The sample population consisted of laboratory technologists and mortuary attendants in various medical schools, teaching hospitals, general hospital and funeral homes across Nigeria. A total of 72 respondents from twenty-one centres comprising of twelve faculties of anatomy, five general hospitals and four funeral homes were surveyed and each respondents answered some sets of semi-structured and selfadministered questionnaires. The questionnaire detailing the demographic characteristic of the respondent such as age, sex, marital status and educational qualifications, while the second part asked questions related to their knowledge of embalmment methods and principles. Respondents were asked to briefly describe what they know about embalmment techniques, types, and recent methods used. They responded to questions on when last they have attended a workshop, conference or seminar on embalming techniques and the plastination technique. All the respondents participated freely, and confidentiality of information given was assured.

\section{Data analysis}

All values are given as mean \pm standard deviation (SD) with $\mathrm{n}$ values indicating the number of subjects analyzed. Data were evaluated by one-way ANOVA, followed by one tailed Student's t-test for the least significant differences. $\mathrm{P}$ values $<0.05$ were considered statistically significant.

\section{RESULTS}

The age range of the respondent is from 20-64years with the mean age at $44.7 \pm 4.27$ years with more than $70 \%$ of the respondents 
are above 40 years. $94.4 \%$ of the respondents are males and females accounting for just $5.6 \%$. The occupational distributions of the respondents are as shown in (Table 1). $45 \%$ of the respondents have never attended any scientific conference/workshop since they joined the profession and only about $15 \%$ of them have attended any conference or workshop on embalming in the last one year (Figure 1). The majority of the respondent have West Africa Examination Council (WAEC) 25(34.7\%) and 13(18.0\%) are with primary school certificate and $2(2.8 \%)$ have a Master of Science degree and 10(13.9\%) did not disclose their educational qualification (Figure 2). The main reason for embalming are for dissections in medical schools by medical students and their allied health discipline 52(43\%), burial purposes 44(36.4), medico-legal reasons 20(16.5\%) and unclaimed bodies 5(4.1\%) (Figure 3). All the respondents have full knowledge of arterial and refrigeration types of embalming techniques with only $30 \%, 15 \%$ and $2 \%$ of laboratory technologists, mortuary attendants and embalmers respectively with knowledge of plastination (Figure 4).

Table 1: Age, sex and occupational distributions of respondents, asterisk indicates high rate of male's respondent in the study.

\begin{tabular}{lll}
\hline Age (Years) & Frequency & Percentages (\%) \\
\hline $20-24$ & 1 & 1.4 \\
$25-29$ & 5 & 6.9 \\
$30-34$ & 6 & 8.3 \\
$35-39$ & 9 & 12.6 \\
$40-44$ & 12 & 16.7 \\
$45-49$ & 13 & 18.0 \\
$50-54$ & 16 & 22.2 \\
$55-59$ & 6 & 8.3 \\
$60-64$ & 4 & 5.6 \\
& 72 & 100 \\
& & \\
Sex & Frequency & Percentages $\mathbf{( \% )}$ \\
Male & $68^{*}$ & $94.4^{*}$ \\
Female & 4 & 5.6 \\
Total & 72 & 100 \\
& & \\
Occupation & Frequency & Percentages $(\%)$ \\
Technologist & 30 & 41.7 \\
Mortuary attendants & 35 & 48.6 \\
Embalmers & 7 & 9.7 \\
Total & $\mathbf{7 2}$ & $\mathbf{1 0 0}$ \\
\hline
\end{tabular}




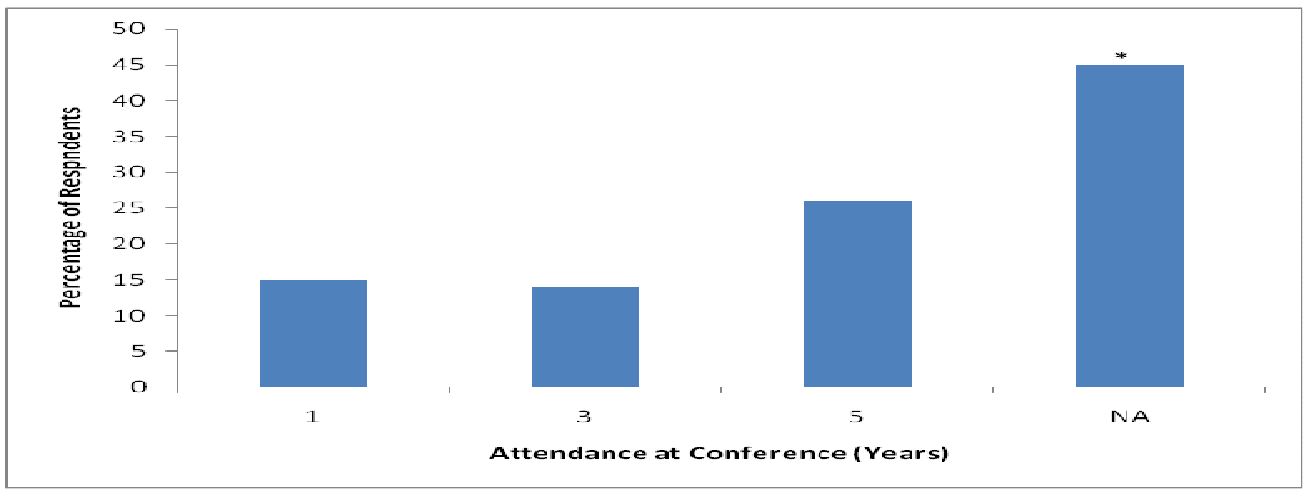

Figure 1: Percentages of respondents and their attendance of scientific conferences and workshops. NA refers to the percentage of those who had never attended any conference(s) or workshop since practising the profession and the asterisk indicates its level of significance at $\mathrm{P}<0.05$.

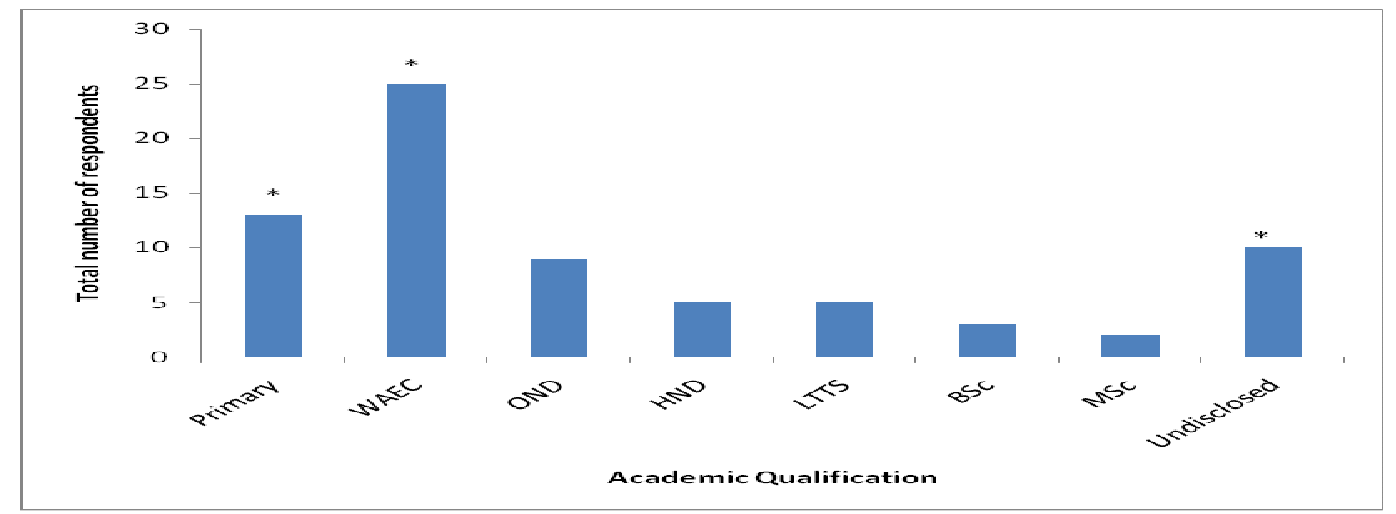

Figure 2: Academic qualification of respondents. This shows that majority of them have secondary school education and below. The "undisclosed" apply to those without any form of formal education. Asterisk indicates the significant high value in the groups.

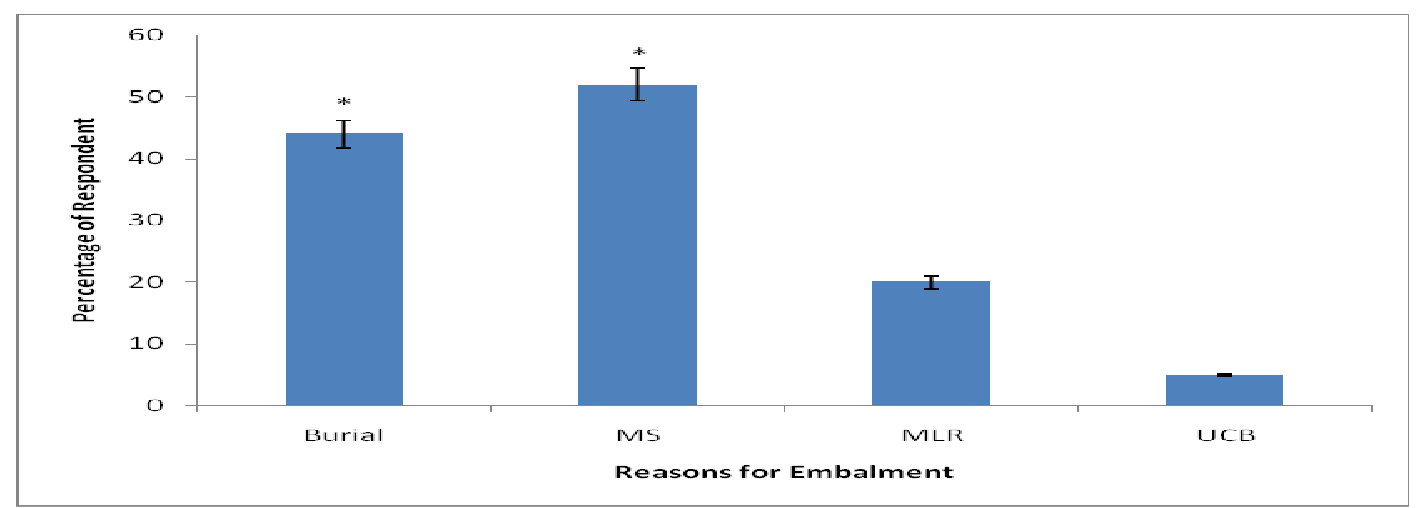

Figure 3: Reasons for embalming are burial, for medical schools (MS), medico-legal reasons (MLR) and unclaimed bodies (UB). The asterisk indicates the level of significant within the groups. 


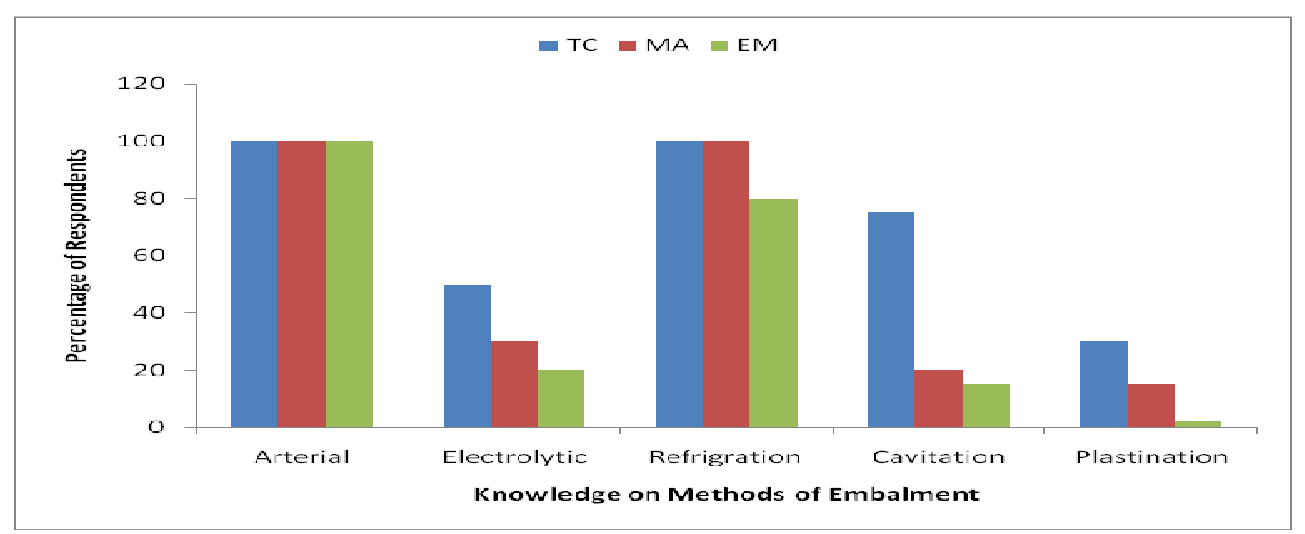

Figure 4: Multiple bar charts showing the knowledge of respondents on various types of embalment, laboratory technologists (TC), mortuary attendants (MA) and embalmers (EM).

\section{DISCUSSION}

The reasons for constant and continuous training in embalming techniques are due to the fact that, different processes are now used when bodies are embalmed for dissection by medical students as the priority here is long term preservation and not mere presentation of the bodies. There are increasing reasons for different types of embalming techniques used, since in most cases, the embalmed tissues are not used only for anatomical dissection but also in research especially in vascular system, joint kinematics and in some cases, histological examination (Ikeda et al., 1993). In some developing countries like Nigeria, complicated machines or apparatus for the injection of embalmer solutions are not readily available and the infusion is means of gravity-fed system (Emery and Marshal, 1991).

Embalming as practiced in funeral homes across the globe uses several steps, however, modern embalming techniques are not a result of a single practitioner but are results of accumulation of many decades of research, trial and errors and intervention with standardized version based on variation in techniques (Frederick and Strub, 1989). The most reason while embalmment is done from the study was burial purposes and this was more common among the Christian community of the country. Archeson (1983) and Bajracharya and Magar (2006) also reported that the major reason for embalmment was delayed burial to allow the relatives of the deceased to see corpse for the last time before burial. Medical education and the need to preserve cadavers for the increased need by high numbers of medical schools in the country coupled with increased number of medical and allied students pose a serious challenge to laboratory technologists and other embalmers to familiarize themselves with modern embalming techniques. We earlier reported in one of our studies on reasons for many shortages of cadavers in our various medical school and we came to the conclusion that increased number of medical schools with high number of students that required cadavers for dissections is a major factor accounting for the shortages (Ajao et al., 2008). The medico-legal reasons for embalmment in Nigeria among the technologists and mortuary attendant was low. The reasons for this, especially among the Muslims community, were based on Islamic injunction that encourages immediate burial of the dead. Legal reasons for embalmment in Nigeria as in other part of the world are more common with criminality evaluations for suspected homicides or murder.

Arterial embalming is the most practised among laboratory technologists, mortuary attendants and embalmers in funeral 
homes and they all have a good practical understanding of the techniques involved, but lack the theoretical basis of the process. They often use the refrigeration method as this is convenient and cheap. This was introduced during the American civil war and is still in practice in Nigeria, but the main constraint is the epileptic supply of electricity in the country. All the respondents lacked basic and practical knowledge of plastination and cavitational embalming techniques. This we believe was due to low level of their academic qualification and non attendance of conferences and workshops on embalming techniques to update their knowledge in methods and modern techniques of embalming. There is very little or no research presently or ongoing in the field. The high cost of plastination technique, they claimed was responsible for the absence of it practice in the country. This should not be a major factor since we believe that the high cost is not comparable to its long term benefits and the various medical schools should have no problem training the technologists on it and actually practising it. They are to serve as resource centre for the various medical schools.

The male dominance in the profession still remains a major factor in Nigeria since some cultural practices in the country consider torching of corpses by female as a taboo. Thus, this discourages most women from choosing it as a profession. This we believe will change as time progresses. The low level of educational qualification of the practitioner especially among the funeral homes could explain why attendance of conferences and workshop on embalming techniques was on the down trend. Most of the practitioners came into profession as a last resort for survival and in most cases; they learnt it through apprenticeship without any formal training. We agree with Bajracharya and Magar (2006) submission that, an introductory class or a single lecture on embalming technique and methods be taught to first year medical student and allied medical students to help equipped them with the technical and conventional modern practices in embalming techniques.

The age range of the respondents was also a major factor as more than seventy percent of them are above thirty five years old and above. The need to attract young and competent age group is very important here since experience is vital to successful embalming techniques and to ensure continuity in the field. We believe that if various medical schools across the country introduce courses and workshops into their curriculum on embalming techniques and method, it will popularize the field among young graduates and will aid in drawing the younger generation and women into the profession. Technological advancement is bringing new embalming techniques such as the sorbent technology and Thiel's embalming method (Benkhadra et al., 2010), and these will coexist with the traditional methods of long term embalming in various medical schools in Nigeria. Professional association in Nigeria such as Anatomical Society of Nigeria (ASN) should organize workshops at regular intervals to look into problems of cadaver preservations and presentation. There are needs for regulations on the personnel and the minimum qualifications required by the practitioners in the country to streamline standard procedure and adherence to them. The government should legislate, monitor, evaluate and regulate their practice of embalming services in the country. In conclusion, it should be appreciated that, the modern day embalmment techniques are results of numerous and rigorous research over centuries.

\section{ACKNOWLEDGEMENTS}

We acknowledged the sincerity and cooperation of all the respondents. We thank Mr Abiola E. A. of Department of Anatomy, University of Ilorin, for his generous and critical advice. 


\section{REFERENCES}

Ajao MS, Abdullahi S, Jimoh SA, Olawepo A, Olayaki LA. 2008. The causes of shortages of cadavers in medical schools across Nigeria. The Journal of Tropical Health Sciences, 15(1): 1-4.

Al-Zuhair AGH, Butt MM, Amonoo-Kuofi HS. 1995. Plastination - A modern technique supplementing the teaching of anatomy. Biomed Res, 6: 231-233.

Archenson ED 1983. Embalming history, prospects and challenges. Lancet, 1: 1161.

Armstrong K. 1993. A History of God: the 4,000 Years quest of Judaism, Christianity and Islam. Ballantine Books: New York; 1-45.

Bajracharya S, Magar A 2006. Embalming: An art of preserving human body. Kathmandu University Medical Journal, 4(16): 554-557.

Barker B, Silverton LS. 1998. Introduction to Medical Laboratory Techniques $\left(7^{\text {th }}\right.$ edn). Butterworth \& Co; 1-26.

Ellis H. 2001. Teaching in the dissecting room. Clin. Anat., 14: 149-151.

Ezugworie J, Anibeze C, Akpuaka F. 2009. Trends in the development of embalming methods. The Internet Journal of Alternative Medicine, 7(2): 1540-2584.

Frederick LG, Strub CG. 1989. The Principles and Practice of Embalming (5th edn). Professional Training Schools Inc and Robertine Frederick.

Ikeda A, Fujimoto K, Yashii I, Matsumoto S, Nishitani K, Ikeda K. 1993. Arterial embalming method of the cadaver and its application to research. Kaibogaku Zasshi, 68(4): 410-421.

Jonathan RS. 1979. The First Crusaders. Cambridge Press Limited; 1095-1131.

Koller J, Baumer U, Kaup Y, Etspuler H, Weser U. 1998. Embalming was used in old Kingdom. Nature, 398: 343-344.

Lockhart RD. 1927. The art of learning anatomy. Lancet, 27: 460.

Mayor RG. 2000. Embalming: History, Theory and Practice ( $3^{\text {rd }}$ edn). McGrawAppleton and Lange.

Newell RLM. 1995. Follow the Royal: the case for dissection. Clin. Anat., 8: 124127.

Saeed M, Rufai AA, Elsayed SE. 2001. Mummification to plastination, revisited. Saudi Medical Journal, 22(11): 956-959.

Sivrev D, Miklosova M, Georgieva A, Dimitrov N. 2005. Modern day plastination techniques-successor of Ancient embalmment methods. Trakia Journal of Science, 3(3): 48-51.

Spring CL. 1971. Formaldehyde in today embalming fluid, Cohort study, $15^{\text {th }}$ Annual Conference of Anatomist, Mexico. Path, pp 14-31.

von Hagens G. 1979. Impregnation of soft biological specimens with thermosetting resins and elastomeres. Anat. Rec., 194: 247-255.

von Hagens G, Tiedemann K, Kriz W. 1987. The current potential of plastination. Anat. Embryol., 175(4): 411-421. 